\title{
DESENVOLVIMENTO DE ROTINAS PARA EXTENSÃO DAS CAPACIDADES DOS PROGRAMAS BIM
}

\author{
Sofia Henriques ${ }^{(1)}$, Luís Ribeirinho ${ }^{(1)}$ \\ (1) TPF - CONSULTORES DE ENGENHARIA E ARQUITETURA, S.A., Lisboa
}

\begin{abstract}
Resumo
Os programas de modelação BIM têm demonstrado limitações na modelação e apresentam ferramentas pouco adequadas ao desenvolvimento de alguns projetos, devido, não só, às caraterísticas dos próprios projetos, mas também das especialidades envolvidas.

Sendo a TPF Consultores uma empresa multidisciplinar, estes desafios têm-se colocado diariamente. Por isso, tem-se vindo a desenvolver internamente, através do Núcleo de Inovação, rotinas e procedimentos que estendem as capacidades e complementam os programas que se utiliza, de forma a automatizar ações de rotina repetitivas, a ajudar a encontrar soluções de projeto, e a colmatar limitações dos programas.

As rotinas apresentadas neste artigo tiveram origem na resolução de questões de projetos específicos, mas a sua forma de aplicação e desenvolvimento tiveram em conta a possível aplicação alargada a outros projetos da empresa.

Apresenta-se de forma sucinta o processo e metodologia de cada rotina: colocação de ancoragens num muro de contenção; ajuste do comprimento de estacas em função da geologia; construção de treliças para uma Obra de Arte; limpeza de Ficheiros Revit a entregar ao cliente ou a partilhar com outros consultores.
\end{abstract}

\section{Introdução}

A TPF Consultores é uma empresa de Engenharia multidisciplinar que desenvolve projetos de várias escalas e para diferentes países. Em 2015 iniciou-se a implementação das metodologias BIM nos vários sectores da empresa. Desde então as disciplinas de Estruturas, Hidráulica, Geologia e Geotecnia têm explorado as potencialidades dos modelos BIM em vários projetos, com resultados muito positivos tanto a nível da qualidade do projeto, como da satisfação das equipas envolvidas.

Durante a primeira fase de implementação, que não aconteceu ao mesmo tempo para todas as equipas, nem teve a mesma duração, foi dado muito enfâse à extração de peças desenhadas, sendo uma preocupação a sua semelhança em relação ao que era produzido em CAD. Os modelos não eram explorados como uma ferramenta de desenvolvimento de projeto, mas sim 
como ferramenta para representação de uma solução final. Com o passar do tempo novas dimensões BIM começaram a ser exploradas, e as várias vantagens trazidas pela utilização dos modelos começaram a ser vistas internamente como uma mais-valia.

A par do aumento de entusiasmo pela exploração dos modelos para o desenvolvimento efetivo de soluções de projeto, surgiram também novos desafios, para os quais o software, como o Revit [1] ou o Civil 3D [2], muitas vezes não tem uma resposta direta, ou responde de forma inadequada. Verifica-se assim uma lacuna do software face à especificidade e complexidade dos projetos desenvolvidos.

Neste sentido, o Núcleo de Inovação da TPF Consultores, criado para dar apoio aos projetos BIM na empresa, tem vindo a ser cada vez mais solicitado para encontrar métodos e processos que ajudem a colmatar lacunas e limitações de software de apoio ao desenvolvimento dos projetos.

O Núcleo tem vindo a desenvolver trabalho para várias áreas e sectores da empresa, no sentido da otimização de processos e rotinas, e para ajudar a encontrar as melhores soluções de projeto, recorrendo à programação e utilização de software complementar.

\section{Rotinas Desenvolvidas}

As rotinas e metodologias desenvolvidas pelo Núcleo de Inovação da TPF Consultores têm origem nas necessidades verificadas pelos projetistas no desenvolvimento do seu trabalho, sendo também uma resposta às metodologias e processos adotados internamente para o desenvolvimento dos projetos segundo a metodologia BIM.

\subsection{Rotinas para Geotecnia e Geologia}

A Geotecnia e a Geologia são disciplinas que ainda não encontram no mercado programas BIM que deem respostas adequadas às questões específicas das suas disciplinas. Apresentamos dois processos, desenvolvidos na TPF Consultores, que recorrem a vários programas, que testam questões de interoperabilidade e que permitiram encontrar respostas de projeto de forma eficiente: colocação de ancoragens num muro de contenção e ajuste do comprimento de estacas em função da geologia.

\subsubsection{Colocação de ancoragens num muro de contenção}

O desenvolvimento deste processo surgiu em resposta a um projeto que iria ser apresentado, na sua versão final, através de desenhos CAD. Apesar dos entregáveis de projeto não contemplarem a entrega do modelo BIM, o recurso ao modelo 3D para o desenvolvimento do projeto e a extração das quantidades, foi visto como uma mais-valia e serviria de projeto-piloto para este tipo de obra.

O recurso a ancoragens num muro de contenção é uma solução construtiva muito utilizada em obras geotécnicas, que, por vezes, se estende por quilómetros. Os cálculos geotécnicos ditam a sua geometria, que pode ser definida através de - espaçamento da malha, distâncias entre níveis e forma da malha (quincôncio ou regular) - que, por sua vez, podem ser traduzidos em fórmulas matemáticas. Tendo em conta este facto, a utilização de modelos tridimensionais aliados a rotinas de distribuição automáticas das ancoragens é uma forma de otimização do processo tradicional e que permite uma contabilização e representação rigorosa da solução proposta. 
Nesse sentido, foi desenvolvido um processo que recorre a vários programas complementares, explorando as suas capacidades de interoperabilidade, e dos quais se quer tirar partido das suas valências específicas que permitem o desenvolvimento do projeto de forma mais dinâmica através dos modelos BIM.

Neste caso, o processo passa pela utilização do software Civil3D e Subassembly Composer, Rhinoceros [3] e Grasshopper [4], Revit e Dynamo [5] (três programas e os respetivos editores de programação visual).

Inicialmente, a secção transversal e o alinhamento do Muro de Suporte são definidos em Civil 3D, sendo a secção tipo definida no Subassembly Composer [6] (Figura 1). O recurso a este editor permitiu parametrizar a seção transversal.

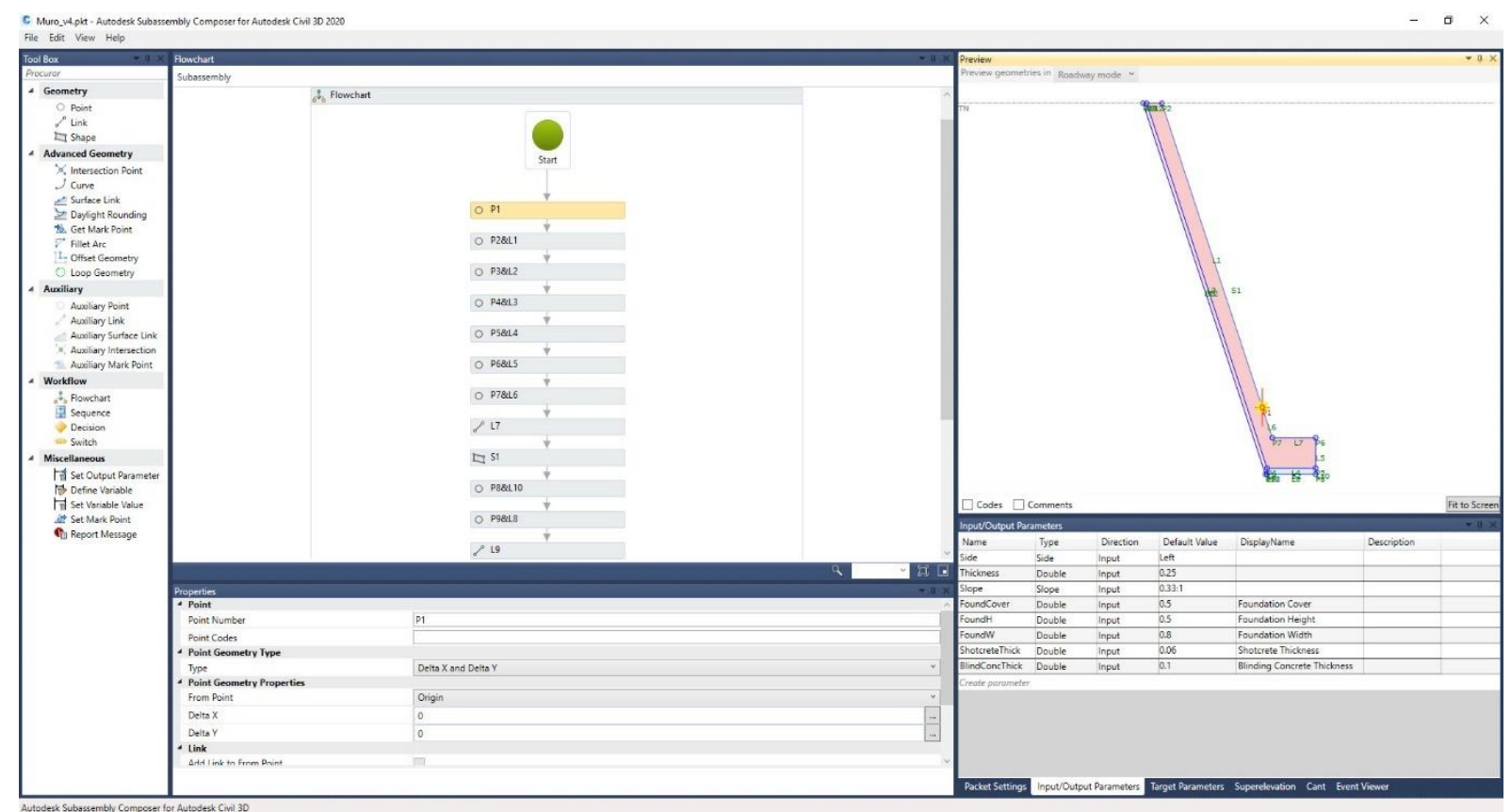

Figura 1: Secção transversal paramétrica do muro em Subassembly Composer 2020.

As linhas que definem a base e o topo do Muro são extraídas do Civil 3D, graças aos códigos introduzidos no subassembly, e importadas no Rhinoceros onde, através do Grasshopper, é possível definir a malha para a colocação das ancoragens (Figura 2).

A rotina desenvolvida, com base nas linhas que vieram do Civil 3D, extrai os pontos das linhas e une dois a dois, um ponto de cada linha, gerando secções verticais ao longo dessas linhas. Os pontos extraídos são definidos pelo Civil 3D, com a frequência que o utilizador definiu. Desta forma é possível identificar a secção mais desfavorável. A partir desta secção, da distância ao topo e do afastamento vertical entre níveis, ambos definidos pelo utilizador, é possível definir as cotas dos níveis e intercetar esses planos com a superfície do muro, gerando os alinhamentos de colocação das ancoragens. O passo seguinte está relacionado com a disposição geométrica das ancoragens - quincôncio ou regular. Depois de definido o afastamento horizontal, pelo utilizador, os alinhamentos são então divididos e os pontos de inserção das ancoragens identificados. Por fim, resta apenas determinar o ângulo em planta das ancoragens. Para isso, é calculado o produto vetorial entre a tangente ao alinhamento dos níveis e a vertical. As 
coordenadas dos pontos de inserção e os respetivos ângulos são exportados para um ficheiro de texto (*.txt) que será interpretado pelo Dynamo.
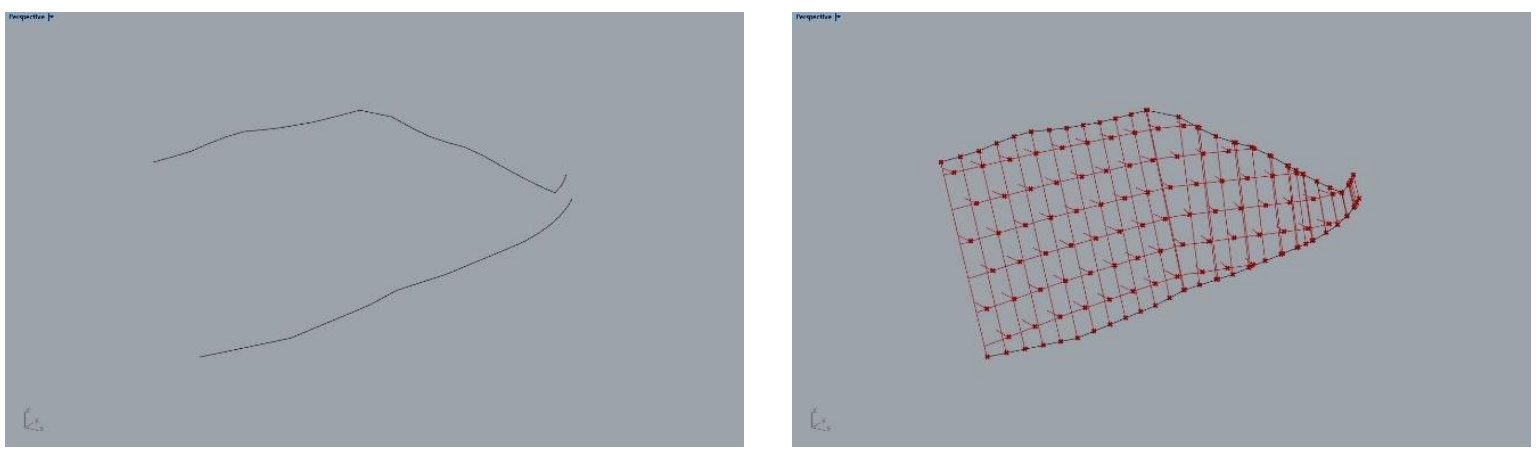

Figura 2: Topo e base do muro à esquerda e malha de ancoragens à direita no Rhinoceros 6.

No Revit, a definição do Muro é obtida através da colocação do sólido em *.dwg exportado do Civil 3D numa família "model in-place". A colocação das ancoragens é feita com recurso a uma rotina de Dynamo (Figura 3). Os dados de entrada são o ficheiro *.txt, gerado no Rhinoceros, a inclinação do muro, e a família da ancoragem a colocar. O resultado final no Revit é apresentado na Figura 4.

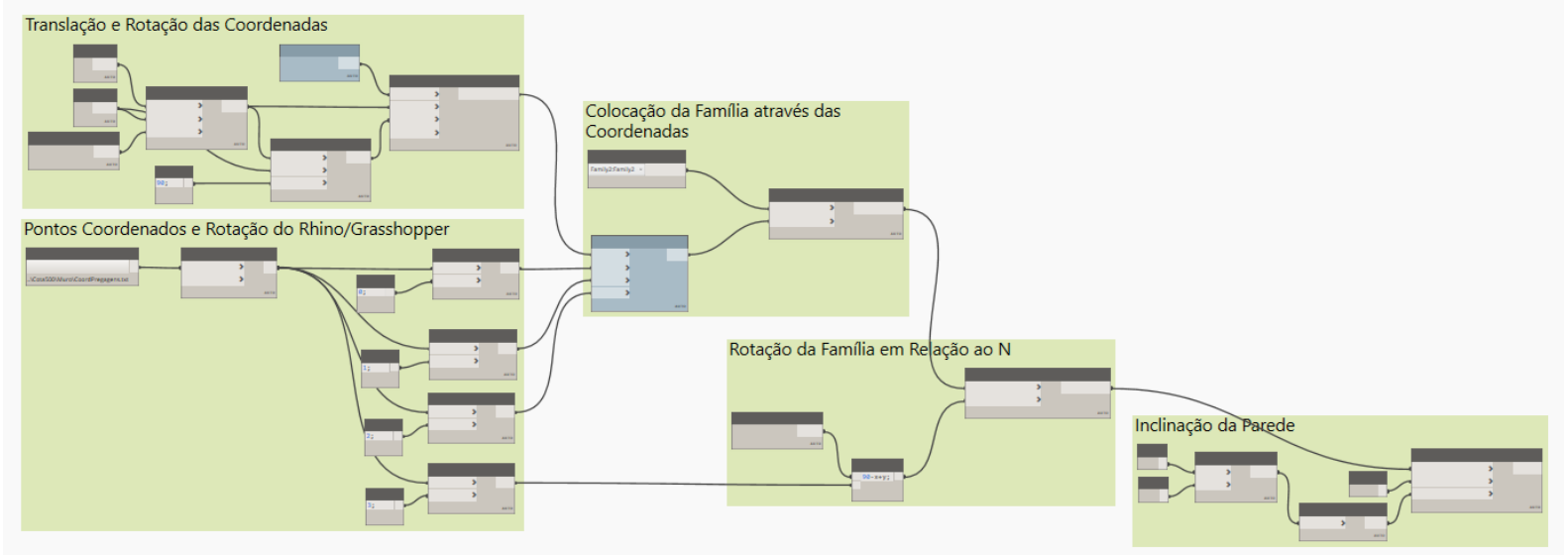

Figura 3: Rotina em Dynamo 2.3.0 para a colocação de ancoragens.

Este processo permite testar várias soluções e afinar o projeto, de forma expedita.

É possível a sua aplicação a vários projetos desta natureza, para a colocação de elementos pontuais num muro de contenção - ancoragens, pregagens, bueiros. 


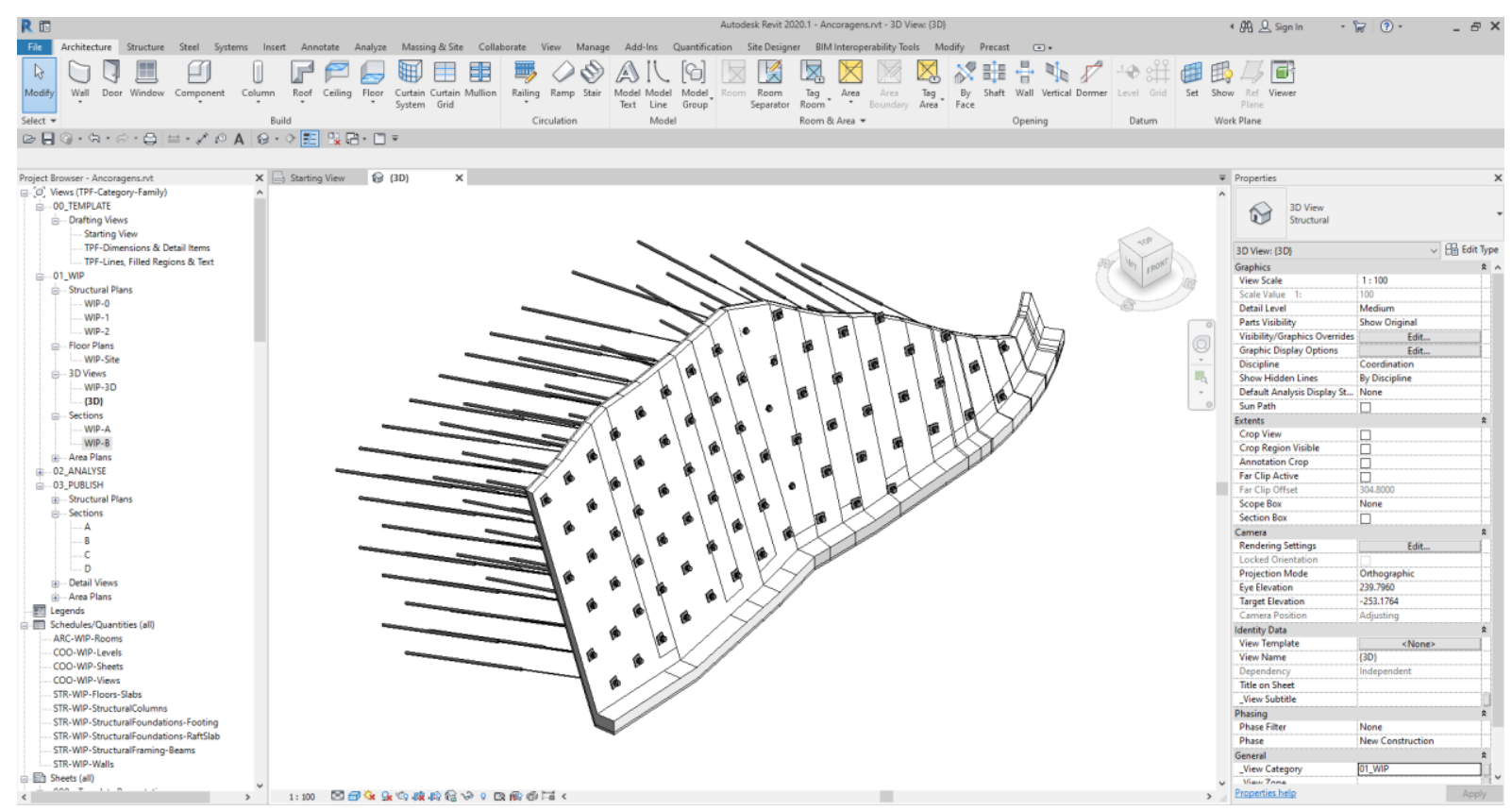

Figura 4: Ancoragens num muro de contenção em Revit 2020.

\subsubsection{Ajuste do comprimento de estacas em função da geologia}

Apesar da existência de software de modelação tridimensional para modelos geológicos, a sua interoperabilidade com modelos BIM é ainda limitada, ou muito dispendiosa, mas a aposta no desenvolvimento de um processo que permitisse essa interoperabilidade surgiu quando, num projeto de grande dimensão, foi necessário calcular o comprimento de 3436 estacas que se deveriam encastrar em determinadas camadas geológicas com andamento variável.

De forma tradicional o comprimento das estacas é calculado por extrapolação de dados obtidos através de um número de cortes limitado, tendo em conta a extensão da área de intervenção. Com a possibilidade de cálculo e ajuste automático do comprimento das estacas (elementos Revit) através de uma rotina de Dynamo (Figura 4), tornou-se possível obter de forma expedita o comprimento total de cada estaca, aumentado o rigor das medições e a possibilidade de representação de cortes rigorosos em qualquer zona do modelo.

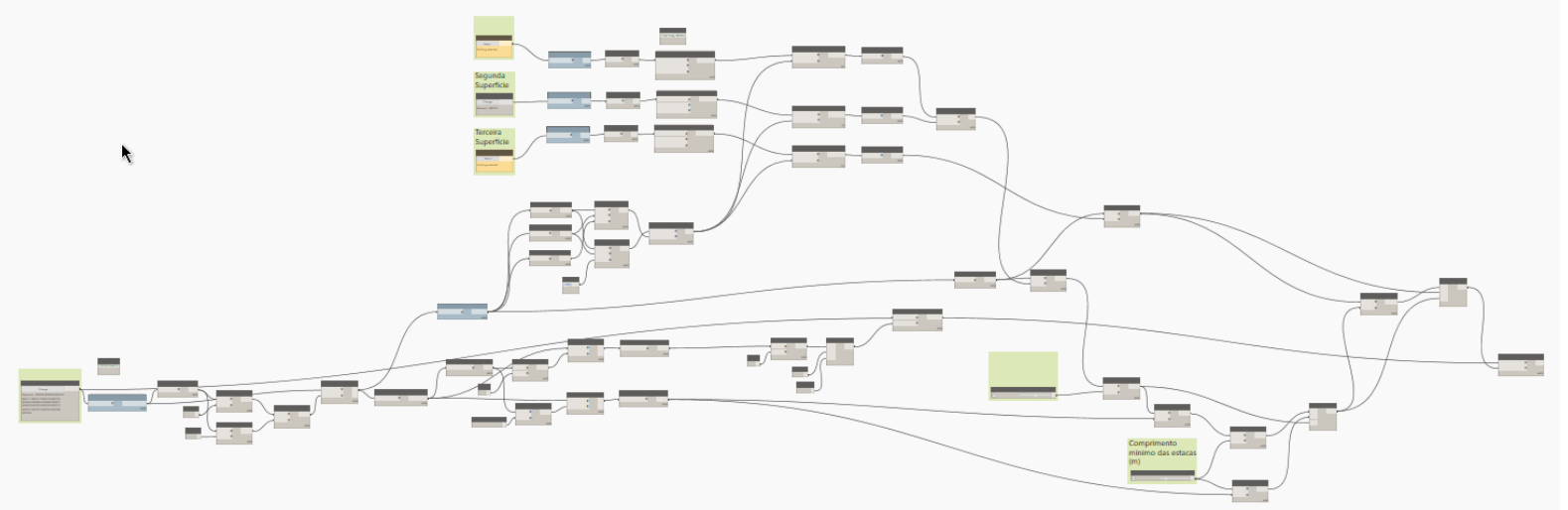

Figura 4: Rotina em Dynamo 2.3.0 para ajuste do comprimento de estacas em função da geologia. 
Neste projeto o modelo geológico foi desenvolvido em Geo5, com base nos dados obtido através dos ensaios de campo. Após a modelação tridimensional da estrutura geológica, os limites foram exportadas no formato *.landXML. Uma das primeiras dificuldades esteve relacionada com um problema de exportação do Geo5 para *.landXML que inverte a posição das coordenadas. A solução encontrada para resolver o problema temporariamente, enquanto não é publicada uma versão do software com esta questão corrigida, foi recorrer ao Civil 3D para extrair as coordenadas dos pontos que constituem as superfícies e gerar novos pontos com as coordenadas corretas, a partir dos quais se geraram novas superfícies. Essas superfícies foram exportadas novamente em *.landXML para serem inseridas no Revit.

No modelo de Revit foram criadas topografias através do ficheiro *.landXML para os vários limites geológicos.

Para executar a rotina de Dynamo é necessário selecionar as estacas, as superfícies e definir o encastramento e o comprimento mínimo das estacas. A rotina permite selecionar 3 superfícies, sendo as duas primeiras superfícies de encastramento. No caso da posição de uma estaca intersetar ambas, o encastramento é feito na superfície mais alta. A terceira superfície está reservada para o substrato rochoso, que prevalece sobre o comprimento mínimo definido.

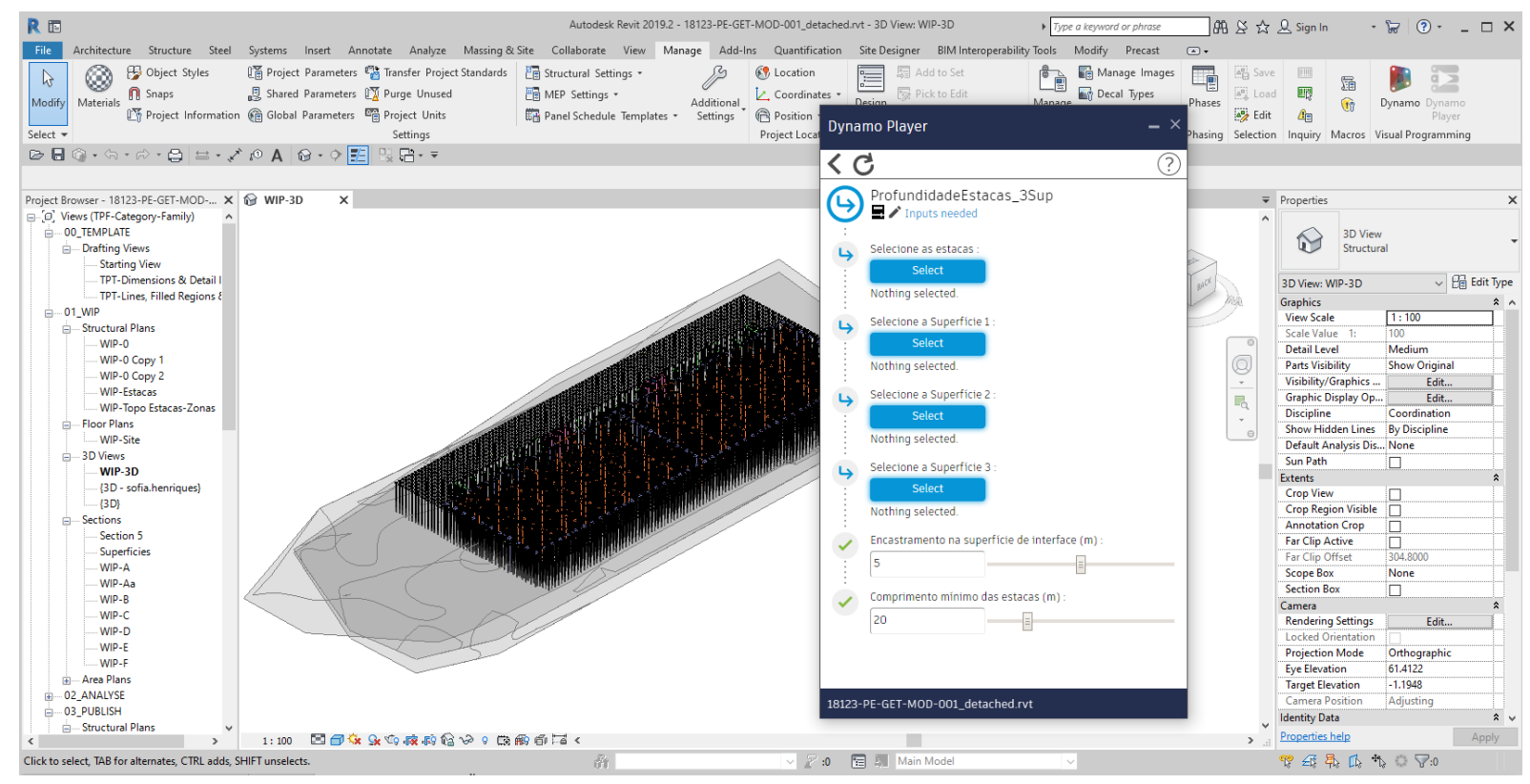

Figura 5: Interface do Dynamo Player no Revit 2019.

Desta forma foi possível calcular e testar várias soluções de forma muito expedita e extrair de forma rigorosa o comprimento de cada uma das estacas.

\subsection{Construção de treliças para uma Obra de Arte}

Uma outra rotina, desenvolvida para um projeto, permite a construção de uma treliça espacial para uma Obra de Arte. Esta é uma rotina que utiliza o programador visual do Revit - Dynamo - que coloca os elementos metálicos da treliça de acordo com os pressupostos de projeto e conforme os parâmetros especificados. 
A colocação dos elementos metálicos em Revit de acordo com o andamento de uma treliça espacial é uma tarefa morosa que implica a definição de planos de trabalho e identificação dos pontos de intersecção entre os elementos.

Neste caso, a rotina escrita no Dynamo tem uma complexidade baixa, mas de grande eficiência na redução do tempo de modelação. A rotina cria uma geometria auxiliar através da construção de linhas que têm como base os limites do tabuleiro da ponte. De acordo com os constrangimentos e premissas de desenvolvimento da treliça, estas linhas definem a posição, direção e comprimento dos elementos metálicos.

Para fazer correr a rotina é necessário aceder ao Dynamo Player (Figura 6) e identificar 3 faces do tabuleiro da ponte (os dois topos e superfície inferior), e definir os parâmetros para a "construção" da treliça espacial: offset em relação aos limites laterais do tabuleiro e aos topos de inícios e fim, altura da treliça, comprimento do módulo e qual o perfil metálico a utilizar.

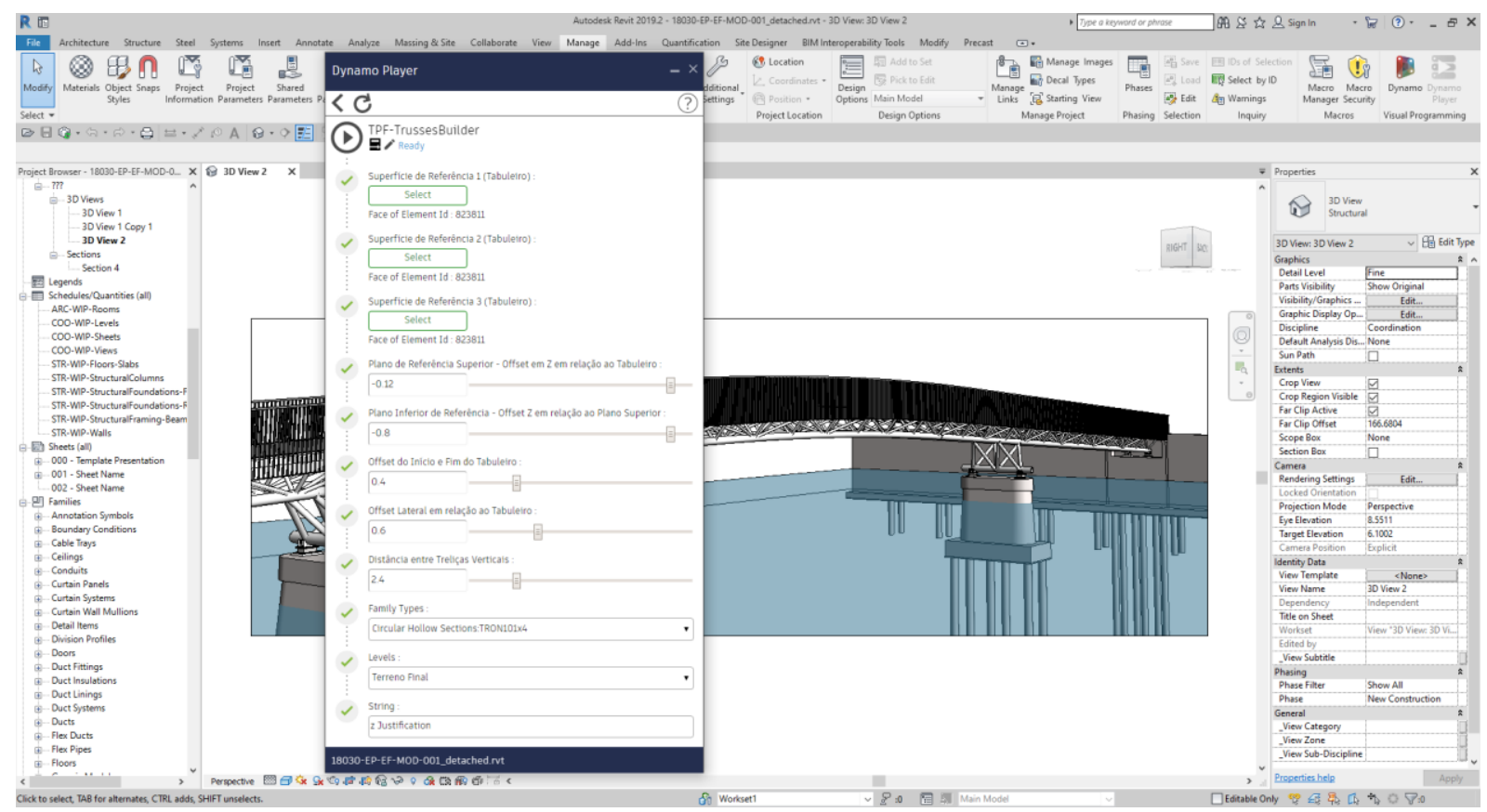

Figura 6: Interface do Dynamo Player no Revit 2019.

Depois de selecionados e definidos os parâmetros no Dynamo Player, a treliça é gerada automaticamente no modelo de Revit.

\subsection{Limpeza de Ficheiros Revit a entregar ao cliente ou a partilhar com outros Consultores}

Uma das rotinas que foi desenvolvida pelo Núcleo de Inovação da TPF Consultores e que é aplicável transversalmente a todos os projetos/modelos, é a rotina de Limpeza de Ficheiros Revit a entregar ao cliente ou a partilhar com outros Consultores.

Os modelos Revit desenvolvidos na TPF Consultores têm uma estrutura de organização definida internamente que facilita o trabalho colaborativo e permite que qualquer colaborador possa navegar sem dificuldade em qualquer modelo. 
As vistas dos modelos estão dividas em dois grandes grupos através da sua classificação no parâmetro _View Category: Work in Progress (WIP) - vista de trabalho e Publish - para publicação. Durante a fase de modelação e de desenvolvimento dos modelos, as vistas de trabalho (WIP) são muito úteis, pois permitirem a anotação e visualização ajustada ao desenvolvimento do trabalho, preservando as vistas para publicação com as anotações e visualização prontas para a entrega do projeto. No entanto, as vistas que não estejam nas folhas para publicação devem ser eliminadas dos modelos antes da sua partilha.

Durante o desenvolvimento do modelo é também expectável que famílias, tipos de famílias, materiais, e outros elementos, que não estejam a ser utilizados, ou sejam obsoletos, permaneçam no modelo. Estes elementos devem ser eliminados regularmente dos modelos, mas em última instância, devem ser eliminados antes do modelo ser entregue ou partilhado com terceiros.

Quando as famílias são desenvolvidas internamente, com base em catálogos comerciais, o URL do catálogo é colocado na família. Contudo, no momento da entrega, não deve haver referência a marcas, principalmente em trabalhos para entidades públicas. Por esse motivo, a informação do parâmetro URL é apagada de forma sistemática de todas as famílias.

Esta limpeza deve ser efetuada a todos modelos antes de serem exportados para IFC.

No sentido de facilitar o trabalho de limpeza do ficheiro, foi desenvolvida uma rotina em Dynamo que:

- Faz um purge do modelo;

- Apaga a informação do parâmetro URL de todas as famílias;

- Elimina as vistas que não estão colocadas em folhas, mas mantém todas as vistas que estão classificadas como 03_PUBLISH no parâmetro _View Category;

- Elimina as tabelas cujo nome não contenha PUB.

Com esta rotina garante-se a entrega de ficheiros com um menor tamanho, e que apenas transportam a informação necessária para o projeto.

\section{Conclusão}

$\mathrm{O}$ recurso a vários programas complementares e à programação em projetos BIM tem-se revelado cada vez mais importante no desenvolvimento de projeto na TPF Consultores. A complexidade dos projetos exige soluções para as quais, em alguns casos, os programas utilizados para o desenvolvimento em BIM não estão preparados para dar uma resposta direta, ou revelam limitações.

Tem-se explorado a complementaridade entre os diferentes programas, e as formas mais expeditas de interoperabilidade. Esta interoperabilidade tem sido feita, tanto através de formatos proprietários (DWG), como de formatos abertos (TXT, landXML), optando-se por uns, ou por outros, conforme os formatos disponíveis, na exportação e importação dos diferentes programas, e a capacidade do formato para transportar a informação necessária.

A necessidade de criação destas rotinas partiu de dificuldades de projetos específicos, tendo estas tido uma utilização pontual a par do seu desenvolvimento. Por este motivo as rotinas ainda não adquiriram a maturidade necessária à sua distribuição por todos os colaboradores, estando apenas a ser utilizadas pelos colaboradores afetos aos projetos que desencadearam o seu 
desenvolvimento. Espera-se que no futuro, estas rotinas saiam do ambiente de desenvolvimento e passem para o ambiente de produção.

Apesar de caminharmos no sentido de um universo cada vez mais digital, que nos permite o trabalho à distância e colaborativo através das múltiplas ferramentas que disponibiliza, tem sido fundamental, nesta fase de implementação BIM, a localização física do Núcleo de Inovação (NI) no seio das equipas de Projeto, permitindo uma interação muito próxima entre a equipa do $\mathrm{NI}$ e as equipas de projeto.

A criação do NI em 2016 foi um passo estratégico para o desenvolvimento de ferramentas e processos inovadores de apoio aos projetos, permitindo que um grupo de colaboradores se dedicasse exclusivamente à melhoria e otimização de métodos e processos, criando, por sua vez, condições para que as equipas de projeto se mantivessem focadas no desenvolvimento das melhores soluções de projeto. Este é um investimento com retorno garantido e, na maioria dos casos, rápido. Contudo, apesar de empiricamente ser óbvia a redução do tempo de execução das tarefas automatizadas, existe uma vontade clara de quantificar essa redução. Uma das formas de o fazer é através do registo das utilizações, de maneira a perceber quantitativamente os ganhos e melhorias da implementação destes novos métodos e processos.

\section{Referências}

[1] "Revit," [Online]. Available: https://www.autodesk.pt/products/revit/overview?plc=RVT\&term=1YEAR\&support=ADVANCED\&quantity=1. [Acedido em Fevereiro 2020].

[2] "Civil 3D," [Online]. Available: https://www.autodesk.pt/products/civil3d/subscribe?mktvar002=3360535\% 7CSEM\%7C92762486151174820487kwd321910814556\&plc $=$ CIV3D\&term $=1-$

YEAR\&support=ADVANCED\&quantity=1\&knc_wwm_emea_pt_nc_ggl_civil-3dsem $=\& g c l s r c=a w . d s \&=\& e f \_i d=C j 0 K C Q j w 6 u T 4 B R D 5 A R I s A D w J Q 1 \_T Y X V$. [Acedido em Fevereiro 2020].

[3] "Rhinoceros," [Online]. Available: https://www.rhino3d.com/. [Acedido em Fevereiro 2020].

[4] “Grasshopper,” [Online]. Available: https://www.grasshopper3d.com/. [Acedido em Fevereiro 2020].

[5] "Open source graphical programming for design," Fevereiro 2020. [Online]. Available: https://dynamobim.org/.

[6] "Civil 3D Subassembly Composer," [Online]. Available: https://knowledge.autodesk.com/support/civil-3d/learnexplore/caas/CloudHelp/cloudhelp/2020/ENU/Civil3DSubassemblyComposer/files/GUID-C569F4E7-D548-410E-B7D6-942A927FFD0Bhtm.html. [Acedido em Fevereiro 2020]. 